\title{
Sterilizer Reliability Analysis Using Reliability Block Diagram Based on Failure Identification Through Fault Tree Analysis
}

\author{
Syamsul Bahri' ${ }^{\text {*, }}$,atimah ${ }^{1}$, Saifuddin Muhammad Jalil ${ }^{2}$, A Amri', Muhammad Ilham ${ }^{1}$ \\ ${ }^{1}$ Department of Industrial Engineering, Universitas Malikussaleh, Aceh, Indonesia \\ ${ }^{2}$ Department of Electrical Engineering, Universitas Malikussaleh, Aceh, Indonesia \\ *Corresponding author E-mail: irsyamsul.bahri@ unimal.ac.id
}

\begin{abstract}
Manuscript received 30 Oct 2021; revised 10 Nov 2021; accepted 1 Jan 2022. Date of publication 10 Jan 2022
Abstract

A sterilizer is a pressurized steam vessel used to boil palm oil. The condition of the sterilizer at PT .X often emits steam at the door and body of the stew. Throughout 2020, there were 12 critical components that were frequently damaged, such as ball valve, actuator, exhaust valve, packing door, elbow, condensate nozzle, liner, pipe, condensate valve, strainer valve, pipe flange, and packing flange. Fault Tree Analysis is an analysis tool that graphically translates the combinations of errors that cause system failures. Reliability Block Diagram is a diagramming method for showing how reliability components contribute to the success or failure of a complex system. Based on the results of the failure calculation using fault tree analysis, the probability of failure of the horizontal sterilizer component is the ball valve $12.2 \%$, exhaust valve $10.9 \%$ actuator $6 \%$, door packing $0.24 \%$, elbow $0.24 \%$, condensate nozzle $4.8 \%$, liner $8.61 \%$, $0.25 \%$ pipe, $0.21 \%$ condensate valve, $4.4 \%$ filter valve, $0.22 \%$ pipe flange and $0.27 \%$ packing flange. The reliability value of the horizontal sterilizer from the calculation using the reliability block diagram is $85.69 \%$ if it operates for 8 hours, $62.93 \%$ if it operates for 27 hours, $39.6 \%$ if it operates for 54 hours, $13.34 \%$ if it operates for 117 hours. o'clock. o'clock. o'clock. hours and $1.81 \%$ when operating for 234 hours. To maintain reliability above $60 \%$, the preventive maintenance schedule is: Every 80 hours of operation a door packing inspection is carried out. Every 234 hours of operation, elbow tubing and flanges are checked. Every 300 hours of operation, a pipe inspection is carried out. Every 450 operational hours an inspection is carried out on the ball valve, condensate nozzle, liner, actuator, and exhaust valve. Every 30 hours of operation, valve condensate, filter valves and packing flanges are checked.
\end{abstract}

Keywords: Sterilizer, Reliability Block Diagram, Fault Tree Analysis, Damage.

\section{Introduction}

PT. $X$ is a company engaged in the processing of fresh fruit bunches (FFB) into Crude Palm Oil and Palm Kernel. Palm oil processing is carried out by carrying out a series of continuous processes so that crude palm oil (Crude Palm Oil) and palm kernel (Palm Kernel) can be separated from palm bunches. Errors in certain processes cannot be corrected in subsequent processes. The performance of Palm Oil Companies must follow the standards and principles of palm oil mills, namely to collect as much oil and palm kernel as possible to achieve the desired results. PT. X has a production capacity of 45 tons/hour. It should be noted that the yield at PT.X limited liability company is $18 \%$ for oil and $5 \%$ for kernels.

A sterilizer is a pressurized steam vessel used to boil palm oil. In the palm oil production process, the sterilizer is the first mechanical processing device for oil palm fruit. This sterilizer uses wet steam as a heating medium which comes from the rest of the steam turbine exhaust which is fed to the supply tank or return vessel [1] [2].

The good or bad quality and quantity of processed palm oil is largely determined by the success of the decoction using a sterilizer. Therefore, boiling the fruit must follow the existing provisions and is an absolute thing to do.

The object of this research is a sterilizer used to boil fresh fruit bunches. This is due to the condition of the sterilizer at PT. X, a palm oil company, where steam leaks often occur at the stew door and body sterilizer. Throughout 2020, there were 12 critical components that were frequently damaged, such as ball valve, actuator, exhaust valve, door packing, elbow, condensate nozzle, liner, condensate pipe, condensate valve, strainer valve, pipe flange, and packing flange. This causes the engine performance to be less effective and efficient so that the boiling time becomes longer and the company can experience time losses in the production process, therefore engine damage is something that needs to be considered more wisely. 
Based on this description, this study tries to discuss the problem of failure and analysis of the reliability of sterilizers with the title "Analysis of the Reliability of Sterilization Equipment Using Reliability Block Diagrams Based on Failure Identification Through Fault Tree Analysis". The purpose of this study was to determine the level of reliability and probability of failure of the sterilizer.

\section{Literature Review}

\subsection{Sterilizier}

The sterilizer is a pressurized steam vessel used to boil fresh fruit bunches with steam (steam). The steam used is saturated steam. The use of saturated steam allows the process of hydrolysis / evaporation of water on the fruit, if using dry steam will cause the skin of the fruit to become charred so that it inhibits the evaporation of water in the fruit flesh and can make pressing difficult. process. Therefore, quality control of the steam used as a source of boiling heat is very important to get perfect boiling results. Sterilizers are divided into 2 types, namely horizontal sterilizers and vertical sterilizers.

\subsection{Basic Concepts of Maintenance}

Maintenance is defined as a form of activity carried out to achieve a result that can return an item or maintain it in a condition that can always function. Maintenance is also a supporting activity that ensures the continuity of machines and equipment so that when they are needed they can be used as expected.

\subsection{Failure Analysis}

Failure Analysis is an activity that aims to determine the cause of specific damage to the main equipment, supporting equipment, and equipment installed in the factory. Types of Failure Analysis of the material can be in the form of fracture, crack, or corrosion.

When a failure occurs, an analytical technique is needed to find out the causes that occur and the steps that must be taken to overcome them. The main steps modeled for the troubleshooting process are as follows:

a. Identification

b. Determine the root cause

c. Determine corrective action

d. Validation and verification of corrective actions

e. Standardization

\subsection{Failure Analysis Method}

The failure analysis process relies on collecting the failed components for subsequent examination of the cause or causes of failure using various methods. There are several methods for identifying system failures, namely:

a. Fault Tree Analysis (FTA)

Fault Tree Analysis (FTA) is one of the reliable techniques, where unwanted failures are managed by summing up and presented with pictures. This fault tree analysis method is effective in finding the heart of the problem because it ensures that an undesired event or loss does not originate from a single point of failure.

b. Failure Mode and Effect Analysis (FMEA)

FMEA is a systematic method for identifying and preventing defects in a process before they occur, improving safety and increasing customer satisfaction. Ideally FMEA is carried out at the product development stage[3]-[9].

c. Root Cause Analysis (RCA)

Root Cause Analysis (RCA) is a troubleshooting process to investigate issues, concerns or discrepancies found. RCA requires investigators to find solutions to pressing problems and understand the underlying or underlying cause of a situation and deal with the problem appropriately, thereby preventing the recurrence of the same problem. It may therefore involve identifying and managing processes, procedures, activities, activities, behaviors, or conditions.

\subsection{Reliability Theory}

Reliability or reliability shows the existence or condition of a facility. This condition can be said to be positive or negative. The concept of reliability involves statistical methods. Through this measurement, the company has an overview of the condition of the equipment it owns, so it can predict the maintenance of the equipment. Reliability can also be measured by using the average number of failures in a certain period of time (failure rate). It can also be expressed as the average time between failures [10]-[16].

a. Analysis failure

The failure rate $(\lambda(t))$ is known as the risk value or a function of the error value. This value provides alternative solutions to explain the distribution of damage.

b. Distribution in Failure Analysis

The distribution used in the failure analysis is as follows:

1. Exponential distribution

2. Weibull distribution

\subsection{Reliability Block Diagram}

A reliability block diagram (RBD) is a diagramming method for showing how components of reliability contribute to the success or failure of a complex system. An RBD can be converted into a success tree by replacing the series path with AND gates and parallel paths with OR gates[17]-[23].

\section{Methods}

\subsection{Research Object}

The object of this research is a sterilizer used to boil fresh fruit bunches. This is due to the condition of the sterilizer at PT.X is palm oil company where steam leaks often occur at the stew door and body sterilizer. throughout 2020, 12 critical components fail frequently 


\subsection{Data Collection Method}

The types of data collected in conducting this research are as follows:

a. Main data

Primary data is data obtained directly from the source, observed, and recorded for the first time. In the process of observation, it was obtained about the production process or the working principle of the sterilizer from the initial stage of boiling to the release of FFB. The primary data used is the assessment data of the cause of damage to the sterilizer component based on fault tree analysis.

b. Secondary Data

Secondary data is data obtained indirectly from the source, such as quotes from books, literature, scientific readings, and company archives that have relevance to the theme of writing.

\subsection{Analysis Method}

Based on the results of observations and data collection, data processing was carried out. The analytical method used is through a fault tree analysis approach and reliability block diagrams. The steps to solve the problem in this research are as follows:

a. Recapitulation of Data Collection Results

Recapitulation of questionnaire data and historical engine performance data.

b. Fault Tree Analysis Calculation

1. Creating a Sterilization Failure Tree

2. Creating a Component Failure Tree

3. Calculate the probability of component failure

c. Reliability of Block Diagram Processing (RBD)

1. Calculate the Mean Time Between Failure (MTBF) of each component using the formula:

$$
\mathrm{MTBF}=\frac{\text { Operating time }}{\text { Failure }}
$$

2. Calculate the failure rate using the formula:

3. Calculate the reliability of each component using the formula:

$$
\lambda=\frac{1}{\mathrm{MTBF}}
$$

$$
R=e^{-(\lambda x t)}
$$

\section{Results and Discussion}

\subsection{Data Sterilizer}

The data collected is the horizontal history of the PT. X palm oil company sterilizer for the period July 2020 - June 2021 . This data consists of planned downtime data, sterilizer operating hours data, and sterilizer damage data.

a. Sterilization Operation Time Data

The following is data on the operating time of the horizontal sterilizer at PT. X palm oil company for one year, which can be seen in Table 1. below:

Table 1. PT. X palm oil company Operation Time Data

\begin{tabular}{lc}
\hline Period & Operating Time (hours) \\
\hline July 2020 & 179,8 \\
\hline August 2020 & 152,73 \\
\hline September 2020 & 181,25 \\
\hline October 2020 & 192,93 \\
\hline November 2020 & 149,2 \\
\hline Desember 2020 & 168,67 \\
\hline January 2021 & 180,85 \\
\hline February 2021 & 233,17 \\
\hline Maret 2021 & 120,82 \\
\hline April 2021 & 114,1 \\
\hline Mey 2021 & 207,57 \\
\hline June 2021 & 159,33 \\
\hline
\end{tabular}

b. Data Planned DowntimeSterilizer Horizontal

The following is the downtime data for the horizontal sterilizer plan at PT. X palm oil company for one year, which can be seen in Table 2 below:

Table 2. Data Planned Downtime palm oil company PT. X

\begin{tabular}{lc}
\hline Period & Planned Downtime (Hour) \\
\hline July 2020 & 20 \\
\hline August 2020 & 15 \\
\hline September 2020 & 20 \\
\hline October 2020 & 15 \\
\hline November 2020 & 20 \\
\hline Desember 2020 & 15 \\
\hline January 2021 & 20 \\
\hline February 2021 & 15 \\
\hline
\end{tabular}




\begin{tabular}{ll}
\hline Maret 2021 & 15 \\
\hline April 2021 & 20 \\
\hline Mey 2021 & 15 \\
\hline June 2021 & 20 \\
\hline
\end{tabular}

c. Horizontal Sterilizer Component Failure Data

The following is a summary of the components that fail in the number 1 sterilizer. This failure data is data on the failure of the sterilization component for one year. Data on components that fail in the number 1 sterilizer can be seen in Table 3 . below:

Table 3. Sterilizer Component Failure Data

\begin{tabular}{clc}
\hline No & Component & Number of Failures \\
\hline 1 & Packing door & 11 \\
\hline 2 & Elbow & 4 \\
\hline 3 & Flange Pipe & 4 \\
\hline 4 & Pipe & 3 \\
\hline 5 & Ball Valve & 2 \\
\hline 6 & Nozzle Condensat & 2 \\
\hline 7 & Liner & 2 \\
\hline 8 & Actuator & 2 \\
\hline 9 & Valve Exhaust & 2 \\
\hline 10 & Valve Condensat & 1 \\
\hline 11 & Streiner Valve & 1 \\
\hline 12 & Packing Flange & 1 \\
\hline
\end{tabular}

\subsection{Calculating Sterilization Failures Using Fault Tree Analysis}

a. A failure that causes the machine to stop operating

There are 3 components that cause the engine to stop operating if it fails, namely the ball valve (P1), exhaust valve (P2), and the actuator (P3). The failure tree that causes the machine to stop operating can be seen in Figure 1 below:

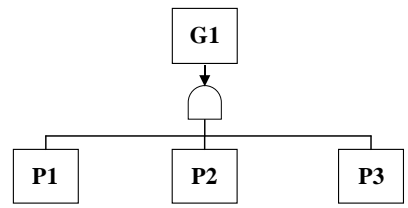

Fig 1. Fault Tree Failure That Causes the Machine to Stop Operating

As for finding the failure value on the components that cause the machine to stop operating, it can be seen as follows:

$\mathrm{P} 1=0.122, \mathrm{P} 2=0.109, \mathrm{P} 3=0.06$

$\mathrm{G} 1=\mathrm{P} 1 \times \mathrm{P} 2 \times \mathrm{P} 3$

$=0.122 \times 0.109 \times 0.06$

$=0.0008=0.8 \%$

b. Failures That Cause Decreased Engine Performance

Nine components that cause engine performance to decrease if it fails are Packing Door (P4), Elbow (P5) and Nozzle Condensate (P6), liner (P7), Condensate Pipe (P8), Condensate Valve (P9), Streiner Valve (P10), flanges pipe (P11) and packing flange (P12). The failure tree that causes engine performance to decline can be seen in Figure 2 below:

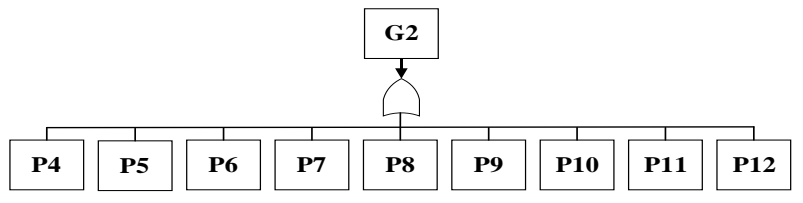

Fig 2. Fault Tree Failures That Cause Decreased Machine Performance

As for finding the failure value on the components that cause the machine to stop operating, it can be seen as follows:

$\mathrm{P} 4=0.0024, \mathrm{P} 5=0.0024, \mathrm{P} 6=0.048, \mathrm{P} 7=0.0861, \mathrm{P} 8=0.0025, \mathrm{P} 9=0.0021, \mathrm{P} 10=0.044, \mathrm{P} 11=0.0022, \mathrm{P} 12=0.0027$

$\mathrm{G} 2=(\mathrm{P} 4+\mathrm{P} 5+\mathrm{P} 6+\ldots+\mathrm{P} 12)$

$=(0.0024+0.0024+0.048+\ldots+0.0027)$

$=0.1798=17.98 \%$

c. Sterilization Failure

There are 2 types of major failures that occur, namely failures that cause the engine to stop operating (G1) and failures that cause engine performance to decrease (G2). The horizontal sterilization failure tree can be seen in Table 4 below: 


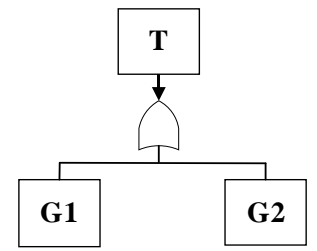

Fig 3. Sterilization Failure Error Tree

Horizontal

As for finding the failure value on the horizontal sterilizer, it can be seen as follows:

$\mathrm{G} 1=0.0008, \mathrm{G} 2=0.1798$

Top Event $=(\mathrm{G} 1+\mathrm{G} 2)-(\mathrm{G} 1 \times \mathrm{x} 2)$

$$
\begin{aligned}
& =(0.0008+0.1798)-(0.0008 \times 0.1798) \\
& =0.1806-0.0001 \\
& =0.1805 \\
& =18.85 \%
\end{aligned}
$$

Based on the above calculation, the probability of failure of the horizontal sterilizer is $18.85 \%$.

Calculating Sterilization Reliability Using the Reliability Block Diagram

As for getting the value of the reliability of the sterilizer at PT.X palm oil company, it can be calculated using the following formula:

1. Average Time Between Failures

The formula for calculating the temporary between failures is as follows:

$$
\mathrm{MTBF}=\frac{\text { Operating time }}{\text { Failure }}
$$

Note: The operating time of the Sterilizer for one year is 2040 hours

The calculation results of the temporary between failure sterilizer can be seen in Table 5 . below:

Table 4. MTBF of Sterilization Components

\begin{tabular}{lcc}
\hline Component & Number of Failures & MTBF \\
\hline Packing door & 11 & 185,49 \\
\hline Elbow & 4 & 510,1 \\
\hline Flange Pipe & 4 & 510,1 \\
\hline Pipe & 3 & 680,13 \\
\hline Ball Valve & 2 & 1020,2 \\
\hline Nozzle Condensat & 2 & 1020,2 \\
\hline Liner & 2 & 1020,2 \\
\hline Actuator & 2 & 1020,2 \\
\hline Valve Exhaust & 2 & 1020,2 \\
\hline Valve Condensat & 1 & 2040 \\
\hline Streiner Valve & 1 & 2040 \\
\hline Packing Flange & 1 & 2040 \\
\hline
\end{tabular}

2. Failure rate

The formula for calculating the failure rate is as follows:

$$
\lambda=\frac{1}{\mathrm{MTBF}}
$$

The results of the calculation of the failure rate can be seen in Table 5. below:

Table 5. Sterilizer Component Failure Rate

\begin{tabular}{lcc}
\hline Component & MTBF & Failure Rate \\
\hline Packing door & 185,49 & 0,005391 \\
\hline Elbow & 510,1 & 0,00196 \\
\hline Flange Pipe & 510,1 & 0,00196 \\
\hline Pipe & 680,13 & 0,00147 \\
\hline Ball Valve & 1020,2 & 0,00098 \\
\hline Nozzle Condensat & 1020,2 & 0,00098 \\
\hline Liner & 1020,2 & 0,00098 \\
\hline Actuator & 1020,2 & 0,00098 \\
\hline Valve Exhaust & 1020,2 & 0,00098 \\
\hline Valve Condensat & 2040 & 0,00049 \\
\hline Streiner Valve & 2040 & 0,00049 \\
\hline Packing Flange & 2040 & 0,00049
\end{tabular}

3. Calculating the Reliability of Horizontal Sterilizer Components

The formula for calculating component reliability is as follows:

$$
\mathrm{R}=\mathrm{e}-(\lambda \times \mathrm{t})
$$

The results of the calculation of component reliability can be seen in Table 6 below: 
Table 6. Reliability of Sterilizer Components

\begin{tabular}{lccccc}
\hline \multirow{2}{*}{ Component } & \multicolumn{5}{c}{ Reliability In Hours (\%) } \\
\cline { 2 - 6 } & 9 & 54 & 117 & 234 & 1404 \\
\hline Packing door & 95,26 & 74,74 & 53,22 & 28,32 & 0,05 \\
\hline Elbow & 98,25 & 89,95 & 79,5 & 63,21 & 6,38 \\
\hline Flange Pipe & 98,25 & 89,95 & 79,5 & 63,21 & 6,38 \\
\hline Pipe & 98,69 & 92,37 & 84,2 & 70,89 & 12,69 \\
\hline Ball Valve & 99,12 & 94,84 & 89,16 & 79,5 & 25,25 \\
\hline Nozzle Condensat & 99,12 & 94,84 & 89,16 & 79,5 & 25,25 \\
\hline Liner & 99,12 & 94,84 & 89,16 & 79,5 & 25,25 \\
\hline Actuator & 99,12 & 94,84 & 89,16 & 79,5 & 25,25 \\
\hline Valve Exhaust & 99,12 & 94,84 & 89,16 & 79,5 & 25,25 \\
\hline Valve Condensat & 99,56 & 97,39 & 94,43 & 89,16 & 50,25 \\
\hline Streiner Valve & 99,56 & 97,39 & 94,43 & 89,16 & 50,25 \\
\hline Packing Flange & 99,56 & 97,39 & 94,43 & 89,16 & 50,25 \\
\hline
\end{tabular}

4. Reliability of Horizontal Sterilizer at PT. X

The reliability of the sterilizer can be calculated and shown in the reliability block diagram as follows:

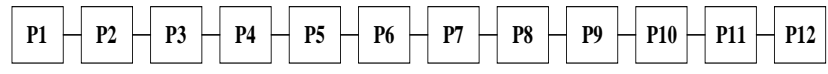

Fig 4. Reliability Block DiagramSterilizer Horizontal

The reliability of the horizontal sterilizer for 9 hours of operation can be seen in the calculation below:

Rsys $=$ R1x R2 x R3xR4 x R5x R6 x R7xR8 x R9x R10 x R11xR12

The results of the calculation of the reliability of the sterilizer using the reliability block diagram can be seen in Table 7 below:

Table 7. Sterilizer Reliability Calculation Results Using Reliability Block Diagram

\begin{tabular}{cc}
\hline Sterilizer Operating Hours & Reliability \\
\hline 9 jam & $85,69 \%$ \\
\hline 27 jam & $62,93 \%$ \\
\hline 54 jam & $39,6 \%$ \\
\hline 117 jam & $13,34 \%$ \\
\hline 234 jam & $1,81 \%$ \\
\hline
\end{tabular}

\section{Conclusion}

Based on the processing that has been done, it can be concluded:

a. The probability of failure of each component of the horizontal sterilizer is different because the cause of the failure of the component is also different. Based on the failed horizontal sterilizer component, there are 3 components (ball valve, exhaust valve, and actuator) that can cause the sterilizer to stop operating, and 9 components (packing door, elbow, condensate nozzle, liner, condensate pipe, condensate valve, filter valve, flanges). pipe and packing flange) which causes the sterilizer to experience a decrease in performance. Then the results of the calculation of the probability of fault tree analysis based on two major failures, the probability of failure of the horizontal sterilizer at PT. X palm oil company is $18.85 \%$.

b. The reliability of horizontal sterilization is different for each hour of operation. The longer the operating hours, the lower the reliability of the sterilizer. The following is the reliability value of the Horizontal Sterilizer at PT. X palm oil company:

1. The reliability of the Horizontal Sterilizer for 9 hours of operation is $85.69 \%$.

2. Horizontal Sterilizer reliability for 27 hours of operation is $62.93 \%$.

3. The reliability of the Horizontal Sterilizer for 54 hours of operation is $39.6 \%$.

4. The reliability of the Horizontal Sterilizer for 117 hours of operation is $13.34 \%$.

5. Horizontal Sterilizer reliability for 234 hours of operation is $1.81 \%$.

With this reliability value, the company is expected to re-evaluate the horizontal sterilizer maintenance schedule.

\section{References}

[1] M. Jiménez-Rosado, V. Perez-Puyana, A. Guerrero, and A. Romero, "Controlled release of zinc from soy protein-based matrices to plants," Agronomy, vol. 11, no. 3, 2021, doi: 10.3390/agronomy11030580.

[2] M. M. Rahman Redoy Akanda and M. A. Hossain, "Smart-devices in Human Behavior Manipula-tion: Process diagram with exploratory assessment," Int. J. Eng. Sci. Inf. Technol., vol. 1, no. 3, 2021, doi: 10.52088/ijesty.v1i3.88.

[3] M. Mardani Shahri, A. Eshraghniaye Jahromi, and M. Houshmand, "Failure Mode and Effect Analysis using an integrated approach of clustering and MCDM under pythagorean fuzzy environment," J. Loss Prev. Process Ind., vol. 72, p. 104591, 2021, doi: https://doi.org/10.1016/j.jlp.2021.104591.

[4] J. Zhu, B. Shuai, G. Li, K.-S. Chin, and R. Wang, "Failure mode and effect analysis using regret theory and PROMETHEE under linguistic neutrosophic context," J. Loss Prev. Process Ind., vol. 64, p. 104048, 2020, doi: https://doi.org/10.1016/j.jlp.2020.104048.

[5] A.-Y. Yu, H.-C. Liu, L. Zhang, and Y. Chen, "A new data envelopment analysis-based model for failure mode and effect analysis 
with heterogeneous information," Comput. Ind. Eng., vol. 157, p. 107350, 2021, doi: https://doi.org/10.1016/j.cie.2021.107350.

[6] G. Huang, L. Xiao, and G. Zhang, "Improved failure mode and effect analysis with interval-valued intuitionistic fuzzy rough number theory," Eng. Appl. Artif. Intell., vol. 95, p. 103856, 2020, doi: https://doi.org/10.1016/j.engappai.2020.103856.

[7] M. J. Kalathil, V. R. Renjith, and N. R. Augustine, "Failure mode effect and criticality analysis using dempster shafer theory and its comparison with fuzzy failure mode effect and criticality analysis: A case study applied to LNG storage facility," Process Saf. Environ. Prot., vol. 138, pp. 337-348, 2020, doi: https://doi.org/10.1016/j.psep.2020.03.042.

[8] H. Li, H. Diaz, and C. Guedes Soares, "A developed failure mode and effect analysis for floating offshore wind turbine support structures," Renew. Energy, vol. 164, pp. 133-145, 2021, doi: https://doi.org/10.1016/j.renene.2020.09.033.

[9] M. Tang and H. Liao, "Failure mode and effect analysis considering the fairness-oriented consensus of a large group with coreperiphery structure,” Reliab. Eng. Syst. Saf., vol. 215, p. 107821, 2021, doi: https://doi.org/10.1016/j.ress.2021.107821.

[10] R. Sireesha, C. Srinivasa Rao, and M. Vijay Kumar, "Graph theory based transformation of existing Distribution network into clusters of multiple micro-grids for reliability enhancement," Mater. Today Proc., 2021, doi: https://doi.org/10.1016/j.matpr.2021.07.067.

[11] T. Cui and S. Li, "System movement space and system mapping theory for reliability of IoT," Futur. Gener. Comput. Syst., vol. 107, pp. 70-81, 2020, doi: https://doi.org/10.1016/j.future.2020.01.040.

[12] L. Wang, Y. Liu, D. Liu, and Z. Wu, "A novel dynamic reliability-based topology optimization (DRBTO) framework for continuum structures via interval-process collocation and the first-passage theories," Comput. Methods Appl. Mech. Eng., vol. 386, p. 114107, 2021, doi: https://doi.org/10.1016/j.cma.2021.114107.

[13] J.-M. Hu, H.-Z. Huang, and Y.-F. Li, "Reliability growth planning based on information gap decision theory," Mech. Syst. Signal Process., vol. 133, p. 106274, 2019, doi: https://doi.org/10.1016/j.ymssp.2019.106274.

[14] P. E. Clayson, K. A. Carbine, S. A. Baldwin, J. A. Olsen, and M. J. Larson, "Using generalizability theory and the ERP Reliability Analysis (ERA) Toolbox for assessing test-retest reliability of ERP scores part 1: Algorithms, framework, and implementation," Int. J. Psychophysiol., vol. 166, pp. 174-187, 2021, doi: https://doi.org/10.1016/j.ijpsycho.2021.01.006.

[15] M. L. Koç and D. Imren Koç, "A cloud theory based reliability analysis method and its application to reliability problems of breakwaters," Ocean Eng., vol. 209, p. 107534, 2020, doi: https://doi.org/10.1016/j.oceaneng.2020.107534.

[16] Y. Liu, L. Deng, W. Zhong, J. Xu, and W. Xiong, "A new fatigue reliability analysis method for steel bridges based on peridynamic theory," Eng. Fract. Mech., vol. 236, p. 107214, 2020, doi: https://doi.org/10.1016/j.engfracmech.2020.107214.

[17] J. Wang, Q. Zhang, S. Yoon, and Y. Yu, "Reliability and availability analysis of a hybrid cooling system with water-side economizer in data center," Build. Environ., vol. 148, pp. 405-416, 2019, doi: https://doi.org/10.1016/j.buildenv.2018.11.021.

[18] J. E. Staley and P. S. Sutcliffe, "Reliability block diagram analysis," Microelectron. Reliab., vol. 13, no. 1, pp. 33-47, 1974, doi: https://doi.org/10.1016/0026-2714(74)90209-1.

[19] W. Ahmed, O. Hasan, and S. Tahar, "Formalization of Reliability Block Diagrams in Higher-order Logic," J. Appl. Log., vol. 18, pp. 19-41, 2016, doi: https://doi.org/10.1016/j.jal.2016.05.007.

[20] G. Kaczor, S. Młynarski, and M. Szkoda, "Verification of safety integrity level with the application of Monte Carlo simulation and reliability block diagrams," J. Loss Prev. Process Ind., vol. 41, pp. 31-39, 2016, doi: https://doi.org/10.1016/j.jlp.2016.03.002.

[21] L. Jia, Y. Ren, D. Yang, Q. Feng, B. Sun, and C. Qian, "Reliability analysis of dynamic reliability block diagram based on dynamic uncertain causality graph," J. Loss Prev. Process Ind., vol. 62, p. 103947, 2019, doi: https://doi.org/10.1016/j.jlp.2019.103947.

[22] J.-P. Signoret, Y. Dutuit, P.-J. Cacheux, C. Folleau, S. Collas, and P. Thomas, "Make your Petri nets understandable: Reliability block diagrams driven Petri nets," Reliab. Eng. Syst. Saf., vol. 113, pp. 61-75, 2013, doi: https://doi.org/10.1016/j.ress.2012.12.008

[23] L. Xie, M. A. Lundteigen, and Y. Liu, "Performance analysis of safety instrumented systems against cascading failures during prolonged demands," Reliab. Eng. Syst. Saf., vol. 216, p. 107975, 2021, doi: https://doi.org/10.1016/j.ress.2021.107975. 